\title{
First synthesis of 1-(indol-2-yl)azulenes by the Vilsmeier-Haack type arylation with triflic anhydride as an activating reagent
}

\author{
Taku Shoji $^{\mathrm{a}, *}$, Yuta Inoue ${ }^{\mathrm{a}}$, and Shunji Ito ${ }^{\mathrm{b}}$ \\ ${ }^{a}$ Department of Chemistry, Faculty School of Science, Shinshu University, Matsumoto 390-8621, Japan \\ ${ }^{b}$ Graduate School of Science and Technology, Hirosaki University, Hirosaki 036-8561, Japan \\ * Corresponding author. Tel.: +81-263-34-2476; fax: +81-263-34-2476; e-mail: tshoji@shinshu-u.ac.jp
}

\section{ARTICLE INFO}

\section{ABSTRACT}

\section{Article history:}

Received

Received in revised form

Accepted

Available online

\section{Keywords:}

Azulene

Indole

Coupling reaction

Electrophilic substitution

Indole derivatives are found in numerous natural products and a number of biologically active pharmaceuticals. Therefore, it is important to develop general methods to synthesize or modify such compounds. ${ }^{1}$ Transition metal-catalyzed cross-coupling reaction is frequently utilized for the synthesis of arylindole derivatives. However, the methods for the preparation of these substances using more readily available reagents are more advantageous. Recently, Shibata et al. have reported electrophilic homo-coupling reaction of indole derivatives with the triflic anhydride $\left(\mathrm{Tf}_{2} \mathrm{O}\right)$ and 2,4,6-tri-tert-butylpyridine as activating reagents. ${ }^{2}$ From a view point of electrophilic cross-coupling reaction, Black and Rezaie have reported the $\mathrm{Tf}_{2} \mathrm{O}$-activated Vilsmeier-Haack $(\mathrm{V}-\mathrm{H})$ type arylation of 2-indolinones with 4,6-dimethoxybenzofuran to give 2-indolylbenzofurans in good yields. ${ }^{3}$ The electrophilic cross-coupling reactions should have a great potential to provide a facile and an efficient synthetic route for the functionalization of indole derivatives because the reactions do not require any expensive transition metal catalyst, aryl halide and a metallic coupling reagent such as boranes and stannanes.

Azulene $\left(\mathrm{C}_{10} \mathrm{H}_{8}\right)$ has attracted the interest of many research groups owing to its unusual properties as well as its beautiful blue color. ${ }^{4}$ We have recently reported the synthesis of several arylazulene derivatives by the transition-metal catalyzed cross-coupling reactions. ${ }^{5}$ More recently, we have also demonstrated a new and two-step strategy for the heteroarylation of azulenes at the 1-, 1,3-, 5- and 5,7-positions by the reaction with the triflate of N-containing heterocycles. ${ }^{6}$ Although many aryl- and heteroarylazulenes have been synthesized as described in the literatures, the carbon-carbon bond formation between azulene and indole derivatives has never been reported so far. ${ }^{7}$ If the $\mathrm{Tf}_{2} \mathrm{O}$-activated $\mathrm{V}-\mathrm{H}$ type arylation of 2-indolinones proceeds with azulene derivatives at the 1-position, a new and facile synthetic route to 1-(indol-2-yl)azulene derivatives will be established. Moreover, success of the one-step synthesis of 1-(indol-2-yl)azulenes would provide a novel possibility for the directive heteroarylation methodology of azulene derivatives using the electrophilic substitution reaction.

We report herein the first synthesis of 1-(indol-2-yl)azulenes by the $\mathrm{Tf}_{2} \mathrm{O}$-activated $\mathrm{V}-\mathrm{H}$ type arylation of 2-indolinones with azulene derivatives.

As a preliminary experiment for the synthesis of 1-(indol-2-yl)azulenes, the $\mathrm{Tf}_{2} \mathrm{O}$-activated $\mathrm{V}-\mathrm{H}$ type arylation of 2-indolinone with azulene (1) was examined in five different organic solvents (Scheme 1). As summarized in Table 1, yields of the product were significantly depended on the solvent employed. The reaction of $\mathbf{1}$ with 2-indolinone in dichloromethane in the presence of $\mathrm{Tf}_{2} \mathrm{O}$ gave the desired 1-(indol-2-yl)azulene (2) in $89 \%$ yield (entry 1). ${ }^{8}$ When 1,2-dichroloethane and toluene was used as a solvent, compound $\mathbf{2}$ was obtained in $76 \%$ and $75 \%$ yields, respectively (entries 2 and 3). Despite the fact that the highly polar solvent, acetonitrile, was a successful solvent in the $\mathrm{Tf}_{2} \mathrm{O}$-activated Reissert-Henze type electrophilic heteroarylation of azulenes, ${ }^{9}$ the yield of the reaction to give $\mathbf{2}$ was moderate with acetonitrile as the solvent (59\%, entry 4). The reaction in chloroform was also revealed to be insufficient due to the low product yield (33\%, entry 5), because of the significant decomposition of the product under the reaction conditions. Among the solvents tested, dichloromethane was found to be the best with respect to the yield of the product $(89 \%)$. 
Presumed reaction mechanism of this reaction is illustrated in Scheme 2. Namely, the reaction of $\mathrm{Tf}_{2} \mathrm{O}$ with 2-indolinone forms a Vilsmeier salt analogue, which is attacked by $\mathbf{1}$ at the most reactive site 1-position, to give 1-(indol-2-yl)azulene (2).

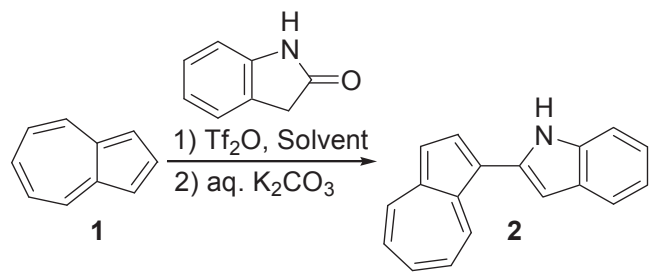

Scheme 1. Reaction of azulene (1) with 2-indolinone.

Table 1. Synthesis of 1-(indol-2-yl)azulene (2)

\begin{tabular}{lll}
\hline Entry & Solvent & Yield of $\mathbf{2}[\%]$ \\
\hline 1 & dichloromethane & 89 \\
2 & 1,2-dichroloethane & 76 \\
3 & toluene & 75 \\
4 & acetonitrile & 59 \\
5 & chloroform & 33 \\
\hline
\end{tabular}
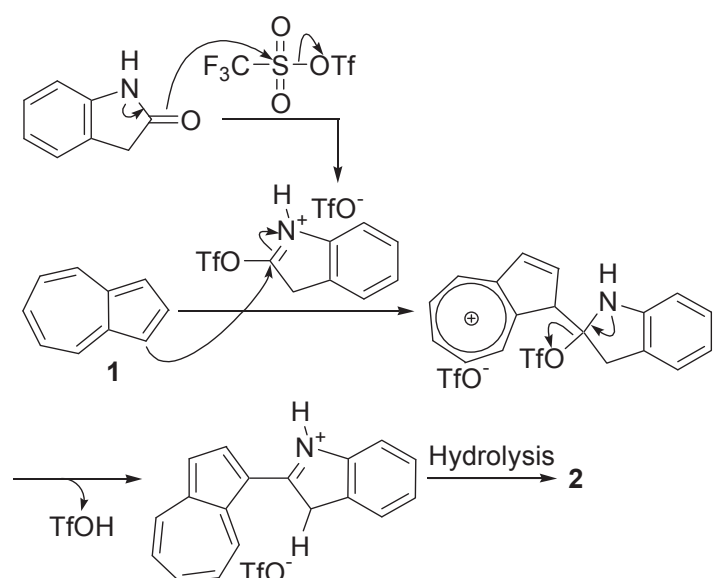

Scheme 2. Presumed reaction mechanism.

To examine the generality of the reaction of 2 -indolinones, we investigated the reaction of $\mathbf{1}$ with three commercially available indolinone derivatives under the optimized reaction conditions (Scheme 3 and Table 2). 5-Chloro-2-indolinone and 6-chloro-2-indolinone were reacted with $\mathbf{1}$ in the presence of $\mathrm{Tf}_{2} \mathrm{O}$ to give the corresponding 1-(5- and 6-chloroindol-2-yl)azulenes (3 and 4) in 91\% and $89 \%$ yields, respectively (entries 1 and 2). The reaction of $\mathbf{1}$ with 1-phenyl-2-indolinone gave the presumed substitution product $\mathbf{5}$ in $27 \%$ yield (entry 3 ). Low yield of the product 5 might be ascribed to the steric effect of the phenyl moiety on the nitrogen atom to the electrophilic reaction. These results show the generality of the $\mathrm{V}-\mathrm{H}$ type reaction of azulene (1) with 2-indolinone derivatives, although the $\mathrm{N}$-phenyl substituent of 2 -indolinone was directly affected toward the product yield.

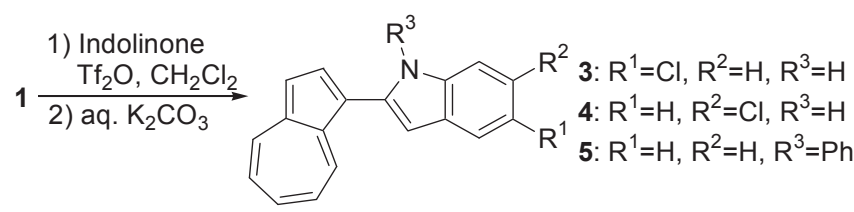

Scheme 3. Reaction of azulene (1) with 2-indolinone derivatives.

\begin{tabular}{llll}
\hline Entry & Indolinone & Reaction time [h] & Product, Yield [\%] \\
\hline
\end{tabular}

A series of azulene derivatives were subjected to this $\mathrm{V}-\mathrm{H}$ type reaction under the optimized reaction conditions to explore the scope of this reaction (Scheme 4). Examined compounds and yield of the products are summarized in Table 3 . The by-products of reaction are also shown in the Figure 1.

The reaction of $\mathbf{6}$ that possess an electron-withdrawing substituent at the 1-position with 2-indolinone in the presence of $\mathrm{Tf}_{2} \mathrm{O}$ in dichloromethane at room temperature gave methyl 1-(indol-2-yl)azulene-3-carboxylate (15) in 71\% yield, along with 22 in $22 \%$ yield (entry 1). Generation of 22 should be attributed to the condensation between the two molecules of $\mathbf{6}$ under the acidic reaction conditions. As similar with $\mathbf{6}$, the reaction of 1-phenylazulene (7) with 2-indolinone under the similar reaction conditions afforded the corresponding substitution product $\mathbf{1 6}$ in $88 \%$ yield (entry 2 ). The substrate $\mathbf{8}$ possessing an electron-donating tert-butyl group at the 6-position afforded the di-substituted product, 6-tert-butyl-1,3-di(indol-2-yl)azulene (23) (13\%) in addition to the desired substitution product 17 (64\%) (entry 3). Formation of the di-substituted product $\mathbf{2 3}$ indicates that tert-butyl group at the 6-position enhances the reactivity toward the $\mathrm{V}-\mathrm{H}$ type reaction, because generation of the di-substituted product was not observed in the reaction of $\mathbf{1}$. The reaction of more electron-rich substrates $\mathbf{9}$ and $\mathbf{1 0}$ resulted into decrease of the product yields (18: $47 \%, 19: 45 \%$ ) due to the decomposition of the products (entries 4 and 5) during the reaction. Furthermore, products $\mathbf{1 8}$ and $\mathbf{1 9}$ were found to be instable under ambient condition and exhibited ready decomposition to give an unidentified complex mixture. Instead of the formation of the presumed indole derivative, 1,1'-biazulene derivative $24^{10}$ was obtained in $43 \%$ yield by the reaction of $\mathbf{1 1}$ under the similar reaction conditions (entry 6). Recently, we have reported the formation of the 3,3'-methylthio-1,1'-biazulene derivative by the treatment of the 1-methylthioazulene with pyridine $\mathrm{N}$-oxide and $\mathrm{Tf}_{2} \mathrm{O} .{ }^{9}$ Therefore, the formation of the 1,1'-biazulene derivative $\mathbf{2 4}$ in this reaction is attributable to the presence of $\mathrm{Tf}_{2} \mathrm{O}$, which should act as an oxidant for the homo-coupling reaction of $\mathbf{1 1}$.

The reaction of the substrates $\mathbf{1 2}$ and $\mathbf{1 3}$ having a phenyl group at the 2-position also afforded the desired products $\mathbf{2 0}$ and 21, respectively, in satisfactory yields. Substrate 12 reacted with 2-indolinone to give 1-(indol-2-yl)-2-phenylazulene (20) in $82 \%$ yield as a sole product (entry 7). From the aspect of the product yield, relatively bulky 2-phenyl substituent did not significantly affect the electrophilic substitution reaction. On the other hand, 2-phenylazulene derivative $\mathbf{1 3}$ bearing a methoxycarbonyl group at the 1-position was converted into indole derivative 21 in $65 \%$ yield, along with decarboxylated product $\mathbf{1 2}^{11}$ in $27 \%$ yield (entry 8).

Contrary to our expectations, the reaction of $\mathbf{1 4}$ afforded indole derivative $\mathbf{2}$ in $72 \%$ yield, whose formation could be ascribed by the ipso-substitution reaction of azulene ring at the 1-position (entry 9). This represents the first example of dihydropyridine moiety acting as a leaving group during the electrophilic substitution reaction in the field of azulene chemistry. Previously, Hafner et al. ${ }^{12}$ and our group ${ }^{13}$ reported 
that 1,3-di-(isopropyl and tert-butyl)azulenes undergo facile electrophilic ipso-substitution reactions such as Friedel-Crafts acylation and Vilsmeier formylation at their 1- and/or 3-positions in good yields. Thus, the dihydropyridyl group on $\mathbf{1 4}$ can be regarded as a good leaving group toward the electrophilic ipso-substitution reaction, likewise the isopropyl and tert-butyl groups.

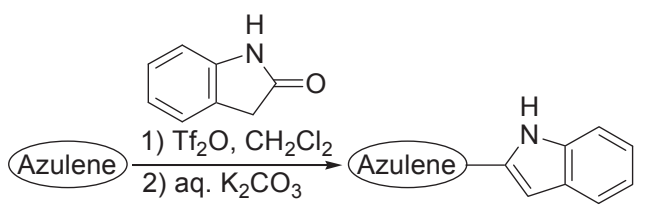

Scheme 4. Reaction of azulene derivatives (6-14) with 2-indolinone.

Table 3. Synthesis of 1-(indol-2-yl)azulene derivatives

\begin{tabular}{|c|c|c|c|c|}
\hline Entry & Azulene & $\begin{array}{l}\text { Reaction } \\
\text { time }[\mathrm{h}]\end{array}$ & Product & $\begin{array}{l}\text { Yield } \\
{[\%]}\end{array}$ \\
\hline 1 & & 2.5 & & 71 \\
\hline 2 & & 3 & & 88 \\
\hline 3 & & 2.5 & & 64 \\
\hline 4 & & 3 & & 47 \\
\hline 5 & & 2 & & 45 \\
\hline & & & $\mathrm{H}_{3} \mathrm{CO}$ & \\
\hline 6 & & 3 & 24 & 43 \\
\hline 7 & & 3 & & 82 \\
\hline 8 & & 6 & & 65 \\
\hline 9 & & 3 & 2 & 72 \\
\hline
\end{tabular}
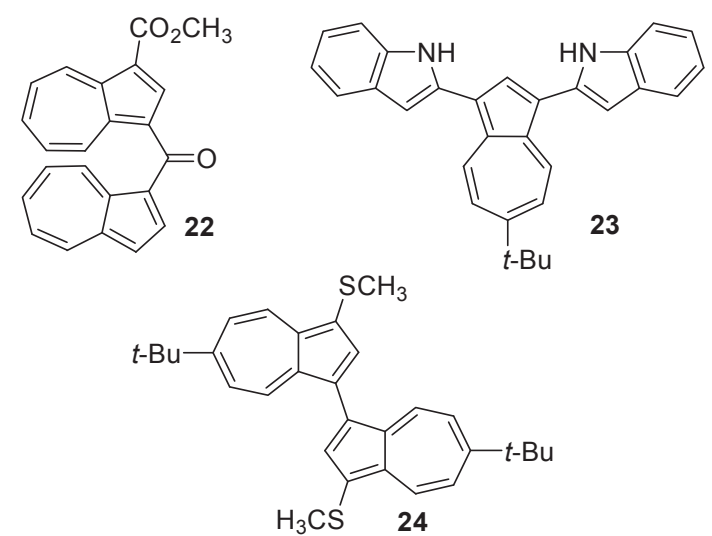

Figure 1. By-products of the $\mathrm{Tf}_{2} \mathrm{O}$-activated $\mathrm{V}-\mathrm{H}$ type reaction.

In conclusion, the $\mathrm{Tf}_{2} \mathrm{O}$-activated $\mathrm{V}-\mathrm{H}$ type reaction of azulene (1) with 2-indolinone has been disclosed. This methodology allowed us to the first synthesis of 1-(indol-2-yl)azulene (2).

The 1-(indol-2-yl)azulene derivatives were available by the reaction of the corresponding azulene derivatives with 2-indolinones in the presence of $\mathrm{Tf}_{2} \mathrm{O}$, following the hydrolysis with aq. $\mathrm{K}_{2} \mathrm{CO}_{3}$. Under the reaction conditions, we found 6-tert-butyl-1-(methylthio)azulene (11) was converted into 1,1'-biazulene derivative 24. By the $\mathrm{Tf}_{2} \mathrm{O}$-activated $\mathrm{V}-\mathrm{H}$ type reaction of 14, novel ipso-substitution was clarified to give 2 in good yield. These results suggest dihydropyridine moiety at the 1-position behaves as a good leaving group, as well as isopropyl and tert-butyl groups. These results would warrant the development of new synthetic methodology for azulene derivatives.

\section{Acknowledgments}

This work was supported by a Grant-in-Aid for Research Activity Start-up (Grant 22850007 to T.S.) from the Ministry of Education, Culture, Sports, Science, and Technology, Japan.

\section{References and notes}

1. (a) Van Order, R. B.; Lindwall, H. G. Chem. Rev. 1942, 30, 69-96; (b) Robinson, B. Chem. Rev. 1963, 63, 373-401; (c) Robinson, B. Chem. Rev. 1969, 69, 227-250; (d) Kochanowska-Karamyan, A. J.; Hamann, M. T. Chem. Rev. 2010, 110, 4489-4497; (d) Matsnev, A.; Noritake, S.; Nomura, Y.; Tokunaga, E.; Nakamura, S.; Shibata, N. Angew. Chem. Int. Ed. 2010, 49, $572-576$

2. Xu, X.-H.; Liu, G.-K.; Azuma, A.; Tokunaga, E.; Shibata, N. Org. Lett. 2011, 13, 4854-4857.

3. Black, D. S. C.; Rezaie, R. Tetrahedron Lett. 1999, 40, 4251-4254.

4. Zeller, K.-P. Azulene in Methoden der Organischen Chemie (Houben-Weyl) (Ed.: Kropf, H.), 4th ed., Thieme, Stuttgart, Germany, 1985, vol. V, part 2c, pp. 127-418.

5. (a) Ito, S.; Inabe, H.; Okujima, T.; Morita, N.; Watanabe, M.; Imafuku, K. Tetrahedron Lett. 2000, 41, 8343-8347; (b) Ito, S.; Inabe, H.; Okujima, T.; Morita, N.; Watanabe, M.; Harada, N.; Imafuku, K. Tetrahedron Lett. 2001, 42, 1085-1089; (c) Ito, S.; Inabe, H.; Okujima, T.; Morita, N.; Watanabe, M.; Harada, N.; Imafuku, K. J. Org. Chem. 2001, 66, 7090-7101; (d) Ito, S.; Okujima, T.; Morita, N. Tetrahedron Lett. 2002, 43, 1261-1264; (e) Ito, S.; Terazono, T.; Kubo, T.; Okujima, T.; Morita, N.; Murafuji, T.; Sugihara, Y.; Fujimori, K.; Kawakami, J.; Tajiri, A. Tetrahedron 2004, 60, 5357-5366; (f) Shoji, T.; Kikuchi, S.; Ito, S.; Morita, N. Heterocycles 2005, 66, 91-94; (g) Ito, S.; Ando, M.; Nomura, A.; Morita, N.; Kabuto, C.; Mukai, H.; Ohta, K.; Kawakami, J.; Yoshizawa, A.; Tajiri, A. J. Org. Chem. 2005, 70, 3939-3949; (h) Shoji, T.; Ito, S.; Toyota, K.; Iwamoto, T.; Yasunami, M.; Morita, N. Eur. J. 
Org. Chem. 2009, 4307-4315; (i) Nakagawa, K.; Yokoyama, T.; Toyota, K.; Morita, N.; Ito, S.; Tahata, S.; Ueda, M.; Kawakami, J.; Yokoyama, M.; Kanai, Y.; Ohta, K. Tetrahedron 2010, 66, 8304-8312; (j) Ito, S.; Shoji, T.; Morita, N. Synlett 2011, 16, 2279-2298.

6. (a) Shoji, T.; Yokoyama, R.; Ito, S.; Watanabe, M.; Toyota, K.; Yasunami, M.; Morita, N. Tetrahedron Lett. 2007, 48, 1099-1103; (b) Shoji, T.; Ito, S.; Watanabe, M.; Toyota, K.; Yasunami, M.; Morita, N. Tetrahedron Lett. 2007, 48, 3009-3012; (c) Shoji, T.; Ito, S.; Toyota, K.; Yasunami, M.; Morita, N. Tetrahedron Lett. 2007, 48, 4999-5002; (d) Higashi, J.; Shoji, T.; Ito, S.; Toyota, K.; Yasunami, M.; Morita, N. Eur. J. Org. Chem. 2008, 5823-5831; (e) Shoji, T.; Ito, S.; Toyota, K.; Morita, N. Eur. J. Org. Chem. 2010, 1059-1069; (f) Shoji, T.; Ito, S.; Higashi, J.; Morita, N. Eur. J. Org. Chem. 2011, 5311-5322; (g) Shoji, T.; Inoue, Y.; Ito, S.; Okujima, T.; Morira, N. Heterocycles 2012, 85, 35-41.

7. The $\mathrm{C}-\mathrm{N}$ bond formation between 2-bromoazulene and indole under the palladium-catalyzed Hartwig-Buchwald's condition was reported by our group. Yokoyama, R.; Ito, S.; Okujima, T.; Kubo, T.; Yasunami, M.; Tajiri, A.; Morita, N. Tetrahedron 2003, 59, 8191-8198.

8. A Typical procedure: $\mathrm{Tf}_{2} \mathrm{O}(203 \mathrm{mg}, 0.72 \mathrm{mmol})$ in $\mathrm{CH}_{2} \mathrm{Cl}_{2}(5 \mathrm{~mL})$ were added at room temperature to a solution of azulene (1) $(67 \mathrm{mg}, 0.52$ mmol) and 2-indolinone (101 mg, $0.76 \mathrm{mmol})$ in $\mathrm{CH}_{2} \mathrm{Cl}_{2}(15 \mathrm{~mL})$. The resulting solution was stirred at the same temperature for 2.5 hours. The reaction mixture was poured into a $2 \mathrm{M} \mathrm{K}_{2} \mathrm{CO}_{3}$ solution, extracted with AcOEt, washed with brine and dried over $\mathrm{Na}_{2} \mathrm{SO}_{4}$. The solvent was removed under reduced pressure and the residue was purified by column chromatography on silica gel with hexane/AcOEt (10:1) as an eluent to give 1-(indol-2-yl)azulene (2) (113 mg, 89\%) as green crystals. ${ }^{1} \mathrm{H}$ NMR $\left(500 \mathrm{MHz}, \mathrm{CDCl}_{3}\right): \mathrm{ppm} ; \delta_{\mathrm{H}}=8.80(\mathrm{~d}, 1 \mathrm{H}, J=9.5 \mathrm{~Hz}, 8-\mathrm{H}), 8.33(\mathrm{~d}, 1 \mathrm{H}$, $J=9.5 \mathrm{~Hz}, 4-\mathrm{H}), 8.25$ (br.s, $1 \mathrm{H}, \mathrm{NH}$ of indole), 8.06 (d, $1 \mathrm{H}, J=4.0 \mathrm{~Hz}$, 2-H), $7.66\left(\mathrm{~d}, 1 \mathrm{H}, J=7.5 \mathrm{~Hz}, 4^{\prime}-\mathrm{H}\right.$ of indole), $7.61(\mathrm{t}, 1 \mathrm{H}, J=9.5 \mathrm{~Hz}$, 6-H), $7.43(\mathrm{~d}, 1 \mathrm{H}, J=4.0 \mathrm{~Hz}, 3-\mathrm{H}), 7.41\left(\mathrm{~d}, 1 \mathrm{H}, J=7.5 \mathrm{~Hz}, 8^{\prime}-\mathrm{H}\right.$ of indole), 7.22-7.13 (m, 4H, 5,7-H, 5,6- $\mathrm{H}$ of indole), 6.79 (s, 1H, 3'- $\mathrm{H}$ of indole) ppm; ${ }^{13} \mathrm{C}$ NMR (125 MHz): $\delta_{\mathrm{C}}=142.19$ (C-8a), $138.78(\mathrm{C}-6)$, 137.63 (C-4), 136.55 (C-8a' of indole), 136.01 (C-8), 135.62 (C-3a), 135.48 (C-2), 134.76 (C-1), 129.54 (C-3a' of indole), 123.93, 123.81, 121.73 (C-7), 120.21, 120.09 (C-4' of indole), 117.93 (C-3), 110.61 (C-8' of indole), 101.20 (C-3' of indole) ppm.

9. Shoji, T.; Okada, K.; Ito, S.; Toyota, K.; Morita, N. Tetrahedron Lett. 2010, 51, 5127-5130.

10. Shoji, T.; Higashi, H.; Ito, S.; Toyota, K.; Asao, T.; Fujimori, K.; Yasunami, M.; Morita, N. Eur. J. Org. Chem. 2008, 1242-1252.

11. The ester function of 2-arylazulenes at the 1-position exhibit decarboxylation under the acidic conditions. (a) Morita, T.; Takase, K. Bull. Chem. Soc. Jpn. 1982, 55, 1144-1152; (b) Morita, T.; Abe, N.; Takase, K. J. Chem. Soc., Perkin Trans. 1 2000, 3063-3070.

12. Hafner, K.; Moritz, K. L. Justus Liebigs Ann. Chem. 1962, 656, 40-53.

13. Shoji, T.; Ito, S.; Okujima, T.; Higashi, J.; Yokoyama, R.; Toyota, K.; Yasunami, M.; Morita, N. Eur. J. Org. Chem. 2009, 1554-1563. 